\title{
The migration of integrated library systems with special reference to the rollout of Unicorn in the province of $K Z N$
}

\author{
Reggie Raju' \\ University of KwaZulu-Natal Libraries \\ rajur@ukzn.ac.za \\ Moodley, S. R. ${ }^{2}$ \\ University of KwaZulu-Natal Libraries \\ moodlesr@ukzn.ac.za \\ Jagarnath, O. $^{3}$ \\ University of KwaZulu-Natal Libraries \\ jagarnat@ukzn.ac.za \\ Chetty, S. ${ }^{4}$ \\ University of KwaZulu-Natal Libraries \\ chettysa@ukzn.ac.za \\ Shongwe, B. ${ }^{5}$ \\ University of KwaZulu-Natal Libraries \\ shongwebl@ukzn.ac.za \\ Raju, J. ${ }^{6}$ \\ Durban University of Technology \\ jayar@dut.ac.za
}

\begin{abstract}
New technological advancements have significantly influenced the development of integrated library systems (ILS). Selecting such an integrated library system, either as an introduction or a replacement, is a complicated process that requires careful planning. However, this selection process becomes even more complicated given the fluidity of the vendor market and the continuous enhancements to integrated library systems. A more recent issue for debate in the selection process is that of 'buying' or 'building'.

The purpose of this paper is to identify, via a review of the literature, the factors that influence the selection of an ILS and the implementation of the migration process. In the context of this review of the literature, this paper discusses the migration of three institutions in the province of KwaZulu-Natal, namely ESAL, the University of KwaZulu-Natal and the eThewini Municipal Library, to such systems. All three institutions have migrated from a common product in Urica to a common vendor and product in SIRSI's Unicorn. Each followed its own strategy of selection and implementation.

A growing trend is the move away from purchasing a system 'off the shelf' to building a system, using open access software, that meets the needs of a particular LIS environment. The authors make the recommendation that there should be an investigation into the possibility of developing a South African ILS product that would ensure the retention of financial resources within the country, the creation of job opportunities for local communities and the generation of local know-how and expertise in this area.
\end{abstract}

Keywords: ILS; integrated library systems, migration, Unicorn

\section{Introduction}

Information technology, in the current electronic environment, has an influence on every facet of library and information service. In the opinion of Zhang (1998: I), advancement in telecommunication and computer technology have already turned library automation into an on-going process in which librarians keep looking for more powerful and reliable systems to improve their services. Coping with automation and integrated library systems has become an indispensable part of library administrators' professional lives. Selecting an integrated library system (ILS), either as an introduction or a

I. Reggie Raju (PhD) is the Head: G.M.J. Sweeney Law Library, UKZN, South Africa.

2. Sagren Moodley is the IT/Electronic Resources Librarian at the Nelson Mandela Medical School Library, UKZN, South Africa.

3. Omesh Jagarnath is a Senior Subject Librarian at the E.G. Malherbe Library, UKZN, South Africa.

4. Sashni Chetty is a Principal Library Assistant at the E.G. Malherbe Library, UKZN, South Africa.

5. Bongiwe Shongwe is the IT User Consultant for the Howard College Campus Libraries, UKZN, South Africa.

6. Jaya Raju (PhD) is an Associate Professor: Department of Library and Information Studies, DUT, South Africa. 
replacement, is a complicated process that requires careful planning (Zhang 1998: I). The authors are convinced of the complexity of the selection process despite the implied trivialization in the comment of Schulman (1996: 32) who states that in less than seven years "the system will assuredly need a major upgrade to next-generation functionality, even if the library has been updating components throughout the life of the system. ... Like any engineering product, new technology advancements are introduced that require major changes in order to utilize them." New technological advancements have significantly influenced the development of integrated library systems.

The continuous enhancements of integrated library systems is in keeping with a fundamental principle governing libraries and that is, to make the 'library' as easily accessible as possible to users. Seeman (2003: 16) supports the views of Khurshid and Kadry (2006) when he reveals that while most library staff have no experience with systems migration, for technical services and systems staff, it is likely to be one of the largest and most complex projects of their careers. The challenges are to make the shift as seamless as possible, to re-invent workflows and re-examine library policy, and to make certain that the public is getting all possible benefits from the new ILS.

Although many libraries are migrating from one system to another, Seeman (2003:16) confirms that "there is surprisingly little written on the subject". The primary discussion in the literature is on retrospective conversions and automating a library. However, the migration to a new system from an established one has far more nuances and complications than automating from a paper-based system (Seeman 2003: 16).

The focus of this paper is on issues such as the choice of system and vendor, the implementation of the migration process and future developments. In this context, the paper discusses the migration of three institutions in the province of KwaZulu-Natal (KZN), namely the Eastern Seaboard Association of Libraries (ESAL) [comprising the Durban University of Technology, Mangosuthu Technikon and the University of Zululand], the University of Kwazulu-Natal (UKZN) and the eThewini Municipal Library (EML), to such systems. All three institutions have migrated from a common product in Urica to a common vendor and product in SIRSI's Unicorn. Each followed its own strategy of selection and implementation.

\section{Literature review}

A noteworthy finding in the review of the relevant literature was the influence of market forces on the LIS sector with regard to integrated library systems.

2.1 Market forces and the vendor

A study conducted by the ALA (2003) found that the market for integrated library systems has become increasingly saturated over the last few years. In response to this saturation, there have been continuous changes to library automation and library systems thus ensuring live markets. Therefore, as argued by Myhill (2000: 89), "it is no surprise that, while [there is] the need to keep software at the cutting-edge of developments in the competitive information environment, huge sums are being invested in product enhancements." It is these enhancements that keep ILS markets alive and libraries interested. However, economic principles of supply and demand and survival of the most powerful have their fair share of influence on the ILS market. This has seen the disappearance of smaller library system vendors who are unable to develop products quickly enough. Pace (2005: 32) concurs on the issue of the influence of market forces on ILS vendors when he points out that "... it is the saturated state of the market--few worlds left to conquer--that has led some vendors into new markets. Saturation, as well as an influx of investment capital, has also led to more market consolidation." On the positive side, the ALA (2003: I) study reports that "mergers and alliances among vendors, new product developments and movement away from legacy systems have created competition among vendors resulting in a product that is more user-responsive." In the South African ILS environment, locally developed systems like Urica have not responded to the need for growth and sophistication which has meant an increasing reliance on overseas vendors and systems such as SIRSI's Unicorn.

Large vendors are developing more powerful systems that offer flexibility and connectivity to increasing uses of the Internet (ALA 2003: 9). Vendors have identified the potential in research and academic libraries which require powerful connectivity, multifunctionality and the usual use of Linux, UNIX, NT servers and Windows 2000 servers for multi-user operating systems. Ownes (2006: 30) argues that academic librarians are becoming more reliant on electronic resources to satisfy patrons' information needs and for seamless searching across print and electronic holdings. The integrated library system, serving as a component of independent electronic resources management systems, demonstrates the potential to integrate, search and expose the "entire library collection" (Ownes 2006: 30). As indicated, vendors are becoming increasingly responsive to the shifting technological needs of research and academic libraries. However, it must not be accepted that the vendors are making every effort to accelerate change. It would seem that the vendors are doing just enough to keep the market satisfied ensuring there is continuation in demand. The comments by Pace (2005: 32) must not be taken lightly when he elucidates that "the traditional ILS is no longer the center of the library automation

SA JnI Libs \& Info Sci 2007, 73(2) 
universe. Nevertheless, the systems will be with us for a long time. And though the names and owners of the vendors will continue to change from time to time, a robust automation marketplace will be around for a long time as well".

Despite the fact that the mute control is slowly being disconnected on the 'silent' debate on home grown integrated library systems, the debate on choice of vendor and product of an ILS still continues.

\subsection{Choice of vendor and system}

The principal elements in the above mentioned debate are the quality of the product, good technical support, and the ability to sustain services and upgrades. Integrated library systems were initially designed to computerize all the manual tasks associated with managing libraries that had large print collections. The acquisitions module facilitates the purchase of books, while the cataloguing module adopted the rules for producing catalogue cards and applied them to creating an electronic bibliographic database. The circulation module automated the business rules of the circulation desk. The serials-control module managed the receipting, distribution and processing of serials and periodicals. The OPAC served as an electronic card catalogue that leveraged the databases and indexes created by the other modules so users could search for and locate materials (Breeding 2006: 32). In tandem with this relatively uncomplicated purpose of ILS, Karetzky (1998: 42) offers some critical questions that need to be addressed when searching for a vendor and a product. These questions are:

- How long the vendor has been developing and selling software for the LIS market?

- How many automated systems has the vendor installed?

- If the vendor does not have a track record of dealing with large libraries, how will the vendor accommodate the library's needs?

- How does the vendor envision its future?

- Is the vendor financially healthy?

Ryan (2004: 7) takes the view that a selection from a small subset of possible ILS products does not augur well as all the products perform the same basic functions. Therefore, there is a need for less traditional methods in making a selection. He moots the point that there is a need to identify the difference between products and vendors and then determine which differences have the most significant influence on an improved service. It must be acknowledged that there is no vendor system that has only strengths, so every system selection involves weighing the relative importance of strengths and weaknesses. The ultimate selection is based on distilled trade-offs which must be weighed against the backdrop of the needs of the users and the views of the staff (Ryan 2004: 6).

The relatively uncomplicated purpose mentioned must be juxtaposed against an arsenal of products that is demanded, in the current technological environment, by a typical academic library. The demands according to Breeding (2006: 33) include, but are not restricted to, the following:

- An ILS for managing the library's physical collections;

- An OpenURL link resolver to provide linking and other access options for electronic content;

- A federated searching tool to make it easier for users to search multiple information resources simultaneously;

- An electronic resource management (ERM) system to help staff manage subscriptions to electronic content products;

- An institutional repository for archiving and accessing scholarly articles or other material produced within the organization; and

- An application for creating and managing local digital content, such as photograph collections, digitized manuscripts, or other special digital collections.

The days of a single, monolithic automation system are coming to an end. Instead, many libraries must work with multiple systems. Although each application deals with its specialized niche in the overall scheme, the applications are interdependent and often involve overlapping content. Given that the ILS is one arm of a highly technologically advanced information provision facility, trade-offs must be the order of the day when choosing an ILS.

\subsection{Implementation of the migration process}

A successful implementation of migration requires considerable commitment from all stakeholders. If the choice is a commercialized product, there has to be formal agreements between the vendor and the library with regard to timeframes. However, Khurshid and Kadry (2006: 87) advise that timeframes must be realistic yet sufficiently flexible to cope with unforeseen delays. The traditional course of action would be to choose the system, configure it, train the staff and then implement using the 'big bang' approach and thereafter 'wait and see'. There is the option of a phased approach which makes provision for some freedom for manipulation and slow configuration ensuring a system that will meet, almost immediately, the needs of the organization. However, this would be a little more costly as the library would have to work with a dual system during the period of transition.

Given that there are huge financial and human resource implications, there is a need for an individual to take charge and steer the ship. Under the directorship of such an individual, the library can make decisions about the approach to be 
adopted for implementation, then configure the system and train the staff. Provision must be made to market the system and do an evaluation.

\subsection{Direction and co-operation}

The substantial investment of finances and human capital must be accompanied by an investment in a director that will smooth the transition into the new system. It is suggested in the literature (Seeman 2003: 16 and Khurshid and Kadry 2006: 76) that the implementation of a new ILS needs the direction of one person to keep the project on track and to ensure that both the library and the vendor meet contractual and procedural deadlines. It is important that there is an individual that can address issues as they arise. Traditionally, the person directing the ILS implementation is the person who heads technical services or the systems department. However, it is good practice to have the person released from his/her job to manage the migration. Significant financial and human resources are invested in the new product, therefore it deserves the dedication of an individual. Ultimately, a well implemented migration will benefit the organization as it will reduce the add-on costs and the system can be utilized to its maximum without undue delay (Seeman 2003: 16).

Seeman further notes that there is a tendency for the library to work independently of the central IT department or alternatively have its own IT department that is reliant on the central IT department for connectivity, bandwidth and such. It is the responsibility of the person directing the implementation process to coordinate with the institution's central IT department. This is a critical component of the work, as the director needs to work with IT for the assigning of domain names, static IP (Internet Protocol) numbers, and other networking issues. It is particularly important for libraries with firewalls and for working with IT staff who suspect turnkey solutions (Seeman 2003: 16).

Bowden (1985: 272) highlights the importance for the director to coordinate the activities of the migration which includes data conversion, staff training, equipment problems and such. The other significant component is for the director to work closely with the new ILS vendor. Similarly, the vendor should appoint a project manager. Cannell and Guy (200I: 148) state that Endeavour has a good project management programme which includes the appointment of a project manager to each site. The appointment of the above mentioned project managers limits complications that may arise when too many people are participating in the decision making process.

The approach to be adopted for the implementation of the migration process is another key consideration for the individuals that are directing the project.

\subsection{2 'Big bang' or phased approach}

It is common practice for libraries to adopt the 'big bang' approach, that is, the implementation of all operations at once. Myhill (2000: 96) accepts that this approach offers "interesting possibilities", however, he does show an inclination to support the phased approach. Myhill indicates that the phased approach follows a more logical and staggered path starting with the catalogue followed by the rest of the activities. He states that the "recent installation of the Unicorn system at the University of Reading provides a good example [of the phased approach]" (Myhill 2000: 96).

Salisbury (1999: 129) describes the phased approach as implemented by the University of Reading. A critical issue for such an implementation is an agreed process with the vendor. Reading started the process in January 1997. The first department to go 'live' in May 1997 was the cataloguing department. By the end of April 1998, the University of Reading, according to Salisbury (1999: 130) had

automated acquisitions, serials and short-loan management; developed a Web-based catalogue, WebCat; introduced self-service holds, automated recalls, self service renewals and short loan bookings; automatic emailing system that generated notices to users; introduced automated claims for serials;...introduced automatic e-mailing notification to academics in departments of new items received in the Library.

This phased approached model projects the view that as staff became familiar or accustomed to their particular module, the Library moved on to the next module. This 'slow' progression allowed staff the opportunity to digest the system and to be confident enough to demand more of the vendor. This is in keeping with the views of authors such as Ryan (2004: 54), Cannell and Guy (200I: 146) and Myhill (2000: 96-97) who encourage 'test driving' the product to understand the product before configuration. It is argued that this approach gives the staff the opportunity NOT to configure in a vacuum. Therefore, it stands to reason that such an approach will augur well in meeting the needs of the library. Further, this phased approached gave the staff at the University of Reading the opportunity to develop confidence in themselves and in the system to the extent that they changed their structure. Salisbury (1999: I36) announced that the automation of the Serials and Acquisitions Department at the University of Reading was relatively straightforward from a systems perspective. "However, it has forced us to look at how these areas are currently organized. It became apparent very quickly that our current organization of separate Acquisitions and Serials department was perhaps not practical in an automated environment" (Salisbury 1999: 136).

The authors conclude that the phased approach had, to some extent, limited guesswork during configuration.

SA JnI Libs \& Info Sci 2007, 73(2) 


\subsubsection{Configuration}

The configuration of the new system is a very important process and must be completed in the best interests of the users of that facility. A system that is efficiently configured will add value to the exploitation of the system by its users. Therefore, every effort must be made to create an environment that is conducive to efficient configuration. This view is supported by Salisbury (1999: 135-136) and Myhill (2000: 92) who indicate that a familiar environment is a major contributor to excellence in configuration. To add to the woes of those configuring the system is the dominance of the North American vendors and the usage of language that is peculiar to them. Terms such as 'patrons' as opposed to 'users', 'checkouts' as opposed to 'issues', 'check-ins' as opposed to 'returns' and such add to the uncertainty that makes the system even more distant from the replacement product.

In the 'big bang' approach, Myhill (2000: 97) recommends that configuration NOT be done in a 'laboratory environment'. He gives the example where a library took delivery of a loan computer onto which the live system was immediately transferred. The use of a 'live system' ensures that configuration is done in an environment where staff members can see the products of their work and be able to evaluate. Such evaluation and hindsight made tweaking of the system more realistic.

As indicated above, Ryan (2004: 54) discusses the principle of test driving the product to create an environment of familiarity during configuration. In the example quoted by Ryan (2004: 54) a library was linked, via a web page, to the online public access catalogue of a customer of the vendor. This access gave the prospective client library insight into the product when they configured a new integrated library system.

It is beyond debate that configuration in a familiar environment does bode well for meeting the needs of the users.

\subsubsection{Training}

The backbone to an efficient implementation and future operation is skilled staff. It therefore becomes even more critical to have structured training sessions for everyone in the library supported by training documentation for ongoing support (Salisbury 1999: 131). Given the priority accorded to training, a number of issues need to be resolved with regard to training. These include who gets trained and by whom; and, does the library negotiate or purchase additional training from the vendor.

It is common practice to identify a core group of staff to be trained by the vendor. Thereafter, training will be based on the principle of cascade training. The authors argue that there is a weak link in this chain as there is an assumption that the person selected for training is au fait with the technology and the system as well as the all the activities of the library.

Seeman (2003: 17) proposes training by the vendor as the vendors' staff know the system well and have experience in teaching others how to use it. An added benefit is that staff resources, that would otherwise be spent on internal training, could be freed. The downside of paid training is that while the trainers may have technical skills, they do not have the dayto-day, frontline experience of those from the library. Further, vendor-supplied training might be more generic than the library's needs to move forward. Lastly, this route leaves no one on the staff with the experience to train subsequent employees.

The ALA (2003: 25) recognizes that staff time is often a hidden cost that goes unchecked or evaluated. The ALA is forthright about cost-effectiveness with regard to training and posed the following questions:

- "Is sending only key staff and having them train others more cost-effective than training all staff upfront?"

- "Which is more cost effective - to have the trainer's expenses paid and bring the training on-site or pay for staff to travel out for the training?"

There is a tendency for libraries to skirt around the above mentioned questions in favour of the traditional method of cascade training.

\subsubsection{Communication}

An issue that is taken for granted and is given the lowest priority in the migration process is communication. Migration is a major shift and therefore should demand corresponding priority. A system migration creates enormous change in the lives of staff, especially those who work in circulation, cataloguing, and other technical service departments. Staff need to know what is coming and when. They need to be aware of developments from sources that have jurisdiction to divulge such. The information that staff receive must be authentic and they must be able to express their concerns and have those concerns addressed. The grapevine is an inappropriate source of information which leads to misinformation which in turn breeds reservations about the system and the project team (Seeman 2003: 17).

Bowden (1985: 275) recommends that libraries migrating to a new system should develop a public relations campaign to build awareness of the fact that there is an improved system on its way. The concepts, together with the specifics of the ILS, must be put out to the relevant communities. This is a great opportunity to promote the system that will be available to them. 


\subsubsection{The migration}

There are two very significant processes that take place during migration. The first is the extraction and loading of data from the old system onto the new. The second is the establishment of workflows and work responsibilities which are important for the new system. Seeman (2003: 18) indicates that while this seems fairly intuitive, many libraries do not leave enough time to migrate either or both processes fully, leading to problems that can delay complete implementation.

Seeman (2003: 18) goes on to point out "in the months leading up to migration, librarians often work with test databases and do not actually train on their own data. This is a mistake, as they miss exploring the nuances in the way their data is coded. This is especially true of patron data that is not in a standard MARC format."

It would seem that a successful implementation rests with having enough time to review the data and examine what it looks like in the system. Seeman (2003: 18), who has worked as a librarian, systems person and vendor trainer, advises that,

you might have different attributes of the data-direct issues, such as determining limits, establishing circulation rules, and deciding who can edit materials. Many of these parameters are found in non-MARC fields in the records, and they need to be addressed separately from the basic MARC loading and indexing. When reviewing data, make sure it will let you do what you want to do, which is why it is necessary to train with your own data.

\subsubsection{Evaluation}

Evaluation should be part of every implementation process. Methods of objectivity and systematically assessing the new system should be developed in addition to subjective evaluation. The library should conduct surveys to engage the reaction of the users of the facility, including staff. The objective is to determine usage of the system. Such information will provide the necessary information for tweaking or 'customizing' the system to best serve the interests of the users. Unfortunately, it is only familiarity with the system that will allow staff the opportunity to interrogate the system and offer suggestions for additional changes. It is suggested by Myhill (2000: 95) that each library should have its own preimplementation testing and evaluation stage and the opportunity to make changes, whether minor or substantial.

A post implementation evaluation is important to make the most of the new system. Further, continuous evaluation will provide sufficient information in determining future developments.

\subsection{Future developments}

It is a given that vendors are in the business of selling different packages as it is their survival that is at stake. Further, market forces have a significant influence on their operations.

The authors support the views of Breeding (2005: 39) who points out that library collections have evolved to include an increasing amount of electronic content and this is not a recent development. However, the tools that are used to help librarians manage the content are growing in variety and sophistication. Given the synergy between current and emerging systems, it would be reasonable to anticipate a smooth and 'natural' integration. However, this is not the case as these tools are packaged as separate applications that require significant time and costs for installation, configuration and ongoing operations.

Breeding (2006: 34) goes on to highlight that libraries that are committed to delivering both print and electronic content will need automation products beyond the core ILS to meet their users' needs. Given this reality, there are two key goals to keep in mind when acquiring and implementing components of an information environment. Firstly, the library's environment must be seamless and simple for users to navigate. No matter how complex the system is behind the scenes, there is a responsibility to have a simple and coherent user interface. It is relatively easy to put up several different systems and make the users navigate through them as separate entities. It is more difficult to integrate them in such a way that users are completely unaware of the constituent components. Secondly, it is essential to implement the components of the library's infrastructure efficiently so that it is easier to sustain them. It is important to avoid redundant work and counterproductive workflows (Breeding 2006: 34).

To return to the core issue of this paper, and that is integrated library systems, there has been significant jockeying for the prime spot on the vendor supplier list.

\subsection{Integrated library systems and the fluidity of the vendor system}

In an article published in the journal American libraries (Equity firm buys SirsiDynix 2007: 23) it was revealed that SirsiDynix, one of the few remaining ILS vendors, was bought by Vista Equity Partners, a private firm whose primary focus is the software and technology sector.

The fluidity of the vendor system makes a mockery of the time, effort and finances invested in choosing a vendor and its system. A typical example of the negative implications of the fluidity is the Jordanian experience. Eight universities in Jordan did an extensive evaluation in 2005 of the different systems, including Sirsi's Unicorn, that were on offer and 
eventually settled on Dynix's Horizon as the best fit for the eight Jordanian universities. Implementation was scheduled for March 2006 (Eight Jordanian universities to implement Dynix 2005: 29). In 2006 Dynix merged with Sirsi to form SirsiDynix. A year later (2006) SirsiDynix was sold to Vista. It is claimed that this sale marks the "the beginning of the end of Unicorn with the announcement that Horizon is the strategic product for new development efforts going forward..." (Scott 2006). The question that begs an answer is: What about the effort and resources expended to get to the decision to purchase Dynix's Horizon?

Tennant (2007: 27) acknowledges that ILS transitions are painful even in the best situations and the natural tendency is to avoid changing systems. There is also the tendency, given the traumatic process that it is, to purchase a system off the shelf. However, what needs to be investigated is the cost effectiveness of buying or building.

\subsubsection{Buy or build?}

It is common cause that building is less expensive than purchasing a commercial system, even after factoring in the increased staff required. Tennant (2007: 27) points out that there will be savings on software licensing and support fees. Further, there will be savings in the use of commodity hardware and architecture that allows for scaling up as needed with relatively inexpensive Linux machines.

There is a buzz in the literature about the fact that activities in 2006 point to strategic shifts in library automation (Breeding 2007, Tenant 2007, Wayne 2006). As intimated above, the dynamics of the business environment have changed rapidly in the last two years from a fragmented industry to a highly consolidated one. However, breakthroughs made by open source library automation systems may disrupt the business models of the industry. Breeding (2007: 27) writes that the stage is set for a fundamentally redefined industry in 2007.

\subsubsection{Evergreen}

The instigator of the paradigm shift, that is, the redefined industry, is the Georgia Public Library Service (GPLS). In I999, GPLS went onto the Unicorn system. In June 2004, GPLS announced a new automation strategy that involved a concerted effort to develop an open source automation system to replace Unicorn. By September 2006, all 252 Georgia PINES libraries migrated from Unicorn to the homebred system called Evergreen. The system was written from scratch using next-generation integrated library systems (Breeding 2007, Tenant 2007, Wayne 2006).

\subsubsection{Koha}

Evergreen is not the only success story. Koha, an open source ILS originally developed in 1999 by Kapito Communications from New Zealand, has steadily been gathering its momentum. Breeding (2007: 28) writes that in a bold move, the Nelsonville Public Library serving a seven-branch library structure, migrated from Spydus to Koha, rechanneling the funds it would have expended on sustaining Spydus's further development.

The potential impact of this paradigm shift on the library marketplace, which has recently been dominated by mergers and acquisitions, cannot be overstated. However, the libraries in the province of KZN have adopted the traditional method of picking a system off the shelf for their migration.

\section{A case study of the Eastern Seaboard Association of Libraries (ESAL), University of KwaZulu Natal (UKZN) and eThewini Municipal Libraries (EML)}

The authors note a migration from Urica to Unicorn in three significant institutions in the province of $K Z N$, that is, ESAL, UKZN and EML. In attempting to establish the factors guiding the rollout of the Unicorn integrated library system, semistructured interviews were conducted with representatives from the respective institutions. However, prior to conducting the interviews, there was a review of the relevant literature to identify issues and variables (Kaniki 1999: 19 and Bless and Higson-Smith 2000: 20) influencing the choice of system and its rollout so that these issues and variables may inform the interview process.

Greeff (2005: 296) and May (1999: III) point out the differences between structured and semi-structured interviews. Semi-structured interviews were used as they gave the authors the flexibility to follow up on "interesting issues that emerge during the interview" (Greeff 2005: 296). Further, semi-structured interviews provide guidelines that ensure the same questions are asked of the different respondents (refer to the Appendix) and this is useful for purposes of comparison. The primary respondents interviewed were those that were directing the migration project in each of the three institutions. Three project directors were interviewed. To provide some balance to the information divulged by these directors, seven people at the operational level were also interviewed (two from ESAL, two from UKZN and three from EML). In total there were five interviews for the three institutions of which three were group interviews of two to three people. Two of the project directors agreed to be interviewed individually while the third project director preferred to be interviewed with operational staff. The information gleaned from the interviews informed the discussion on the rollout of the Unicorn system at the three institutions. 
3.1 ILS migration of three KZN institutions

Three large institutions in KZN migrated from the Urica system to Unicorn. The University of Zululand, Mangosuthu Technikon and the Durban University of Technology, as members of ESAL, went 'live' on I5th November 2005. The University of KwaZulu-Natal with its myriad of recently merged campuses went 'live' on I August 2006. EML intends implementing the new system in August 2007.

\section{I.I Choice of vendor and system}

As indicated, all three institutions migrated from the South African developed Urica system to the international Unicorn system owned by Sirsi.

\section{Rationale for the migration from Urica to Unicorn}

Evans (1999) comments that Urica is possibly the system with the longest pedigree of all in the automation systems market. It was developed in the early 1980s and has continued along the same main development track ever since. Since the initial birth of Urica, the system has developed a rich functionality. The database structures have remained relatively unchanged. In order to survive the revolutions of the IT industry, Urica had to restructure the system and has adopted a thin client approach which retains the back end database and allows the use of a thin browser based client.

Sirsi product literature states that it is a stable and profitable privately held company. The Sirsi software application is continually updated and all of their customers still use the same system they originally purchased. The company has been aggressively marketing itself and the introduction of enhanced system features and functions resulted in rapid growth in the late 1990s (Dzurinko 1999).

It is claimed (Dzurinko 1999) that one of the advantages of Sirsi's Unicorn system is that it can be used 'right out-ofthe box':

Libraries will certainly want to add their own logos and local information to the WebCat, customize some cataloging templates, and supply circulation policies and patron and vendor information. But in general, Unicorn can be used with a minimal amount of local screen and field customization. Sirsi provides an Application Program Interface and WorkBench development tools for libraries that want to customize the software for local requirements (Dzurinko 1999).

It does not serve the purpose of this paper to engage in detailed discussion of the advantages and disadvantages of the different systems. The focus will be on the views of the respondents to the issues that persuaded them to choose Sirsi as the preferred product. It is clear that the respondents had similar reasons for migrating to the Unicorn system after ESAL had done substantial research on the viability of the Urica system. The research, conducted by ESAL, revealed a lack of development of the product by the vendor, UKS. Another significant factor mitigating against Urica was the poor support by Universal Knowledge Software (UKS).

The respondents were convinced that the products of the different vendors provided very similar basic functionality. There is correlation between this view and that of Ryan (2004), discussed above. However, the single most decisive factor influencing the migration to Unicorn was the support base. Subsequent to the decision to migrate to Unicorn, Sirsi announced the appointment of UKS as its distributor in Africa. A significant question that now begs resolution is, 'are we back to square one?' The authors believe that there is merit in the comment of Karetzky (1998: 44) who points out that "there are no saints in this process". It is clearly evident that libraries are preys to market forces.

The authors draw inferences from the discussion in the literature to make the assertion that UKS stopped developing the Urica system as the market for the product had reached saturation. Updates or enhancements would not be economically viable - hence the lack of interest in upgrading Urica in favour of supporting a new product and a regeneration of income sources.

The authors corroborate the need to migrate to a new system. However, it would seem that the most cost efficient way to choose a new system in the current environment of mergers and acquisitions is to place the names of the different vendors on a board and then throw the dart. One is never sure as to which organization will be sending the next invoice.

The issue of 'are we back to square one' must also be viewed in the context of the comments made by the interviewees with regard to the level of support. Of the three institutions, one institution deals directly with the United Kingdom (UK), whilst the other two deal via an intermediary in UKS. However, it has been acknowledged that costs are a deterrent when dealing directly with the UK, especially if there is a requirement for more training (which will be discussed later). On the other hand, it is cheaper and easier to deal with a supplier from South Africa.

Notwithstanding the cost implications, it would seem that the institution dealing directly with the UK gets better support. Queries, via email, are dealt with promptly. However, going via an intermediary causes prolonged delays. One of the respondents gave the example of a query that was lodged with the intermediary a few months ago and they are still 
awaiting a response. Another significant comment made was that the office of the intermediary "was not always as knowledgeable and experienced as their UK counterparts".

\subsubsection{Implementation of the migration process}

As identified via the literature, a successful implementation of migration requires commitment from all stakeholders especially management who should invest in the redistribution of staff to reap the benefits of its huge investment.

\section{The migration and a systems department}

The ballpark amount paid by the three institutions together for the migration was around R25 million. Given such a financial investment, in the current climate of reducing budgets for libraries, one must assume that there would be a corresponding investment in human capital to exploit the functionalities of the product to ensure the best possible service to the user community. Hence the respondents were asked about the structure of their systems department. The consortium (ESAL) was in the fortunate position of being able to employ an individual to manage the migration, from a technical perspective. Unfortunately, the other organizations went into the process with the same, if not smaller, pool of systems support. None of the institutions had an experienced and well staffed systems department. It would seem that the practice is to identify personnel with perceived skills who are then thrown in the deep end to manipulate a system that will perform a critical role in information provision.

The authors are of the view that best practice would be to create a well staffed, in terms of numbers and skills, systems department. It would be this systems department, under the leadership of the director of the project (refer to the views of Seeman (2003) and Khurshid and Kadry (2006)) that would engage in researching, choosing and migrating to the new system. Such a department with these responsibilities would be in line with the recommendations of Raju et al. (2007). They propose a "Department of Innovation" to lead an LIS service in becoming a proactive institution rather than operating reactively.

\section{Direction and co-operation}

All three institutions had persons designated to direct the migration process. Two of the three institutions had released the persons from their jobs to direct the migration. In the third institution, the person had to perform her/his job together with directing the migration project.

However, while criticizing the lack of a sufficiently efficient library systems department among the three institutions surveyed, the authors nevertheless find it refreshing that there is excellent co-operation between the libraries and their respective central ICT departments. It has been brought to the attention of the authors that the respective central ICT departments played a significant role in researching and sourcing the necessary hardware for the migration. As indicated above, one of the institutions was fortunate enough to make an ICT appointment for the migration. Another institution placed on record the allocation of a person, from their central ICT department, to give priority to technical issues that may arise from the migration. This excellent relationship between ICT and library is in keeping with the recommendation of Salisbury (1999) with regard to efficient functioning of a system.

The above mentioned relationship must augur well for best practice in terms of meeting the technical expertise in the implementation process. A significant contributor to the exploitation of a new system is efficient configuration. Therefore, it would stand to reason that substantial resources be invested in configuration - this would include a conducive environment and ultimate levels of consultation in terms of depth and width.

\section{Consultation}

There is no debating, from the information gleaned via the interviews, that there has been consultation by the institutions that have/are migrating to the Unicorn system. However, it would seem that there is a difference of opinion in terms of who was consulted and to what level. Management is of the view that they have consulted as widely as possible. However, staff have a differing view. It was reported by one respondent that management made the decision and "people were not consulted and people complained". The management from the same institution reported that there was "lots of input from staff on the ground".

The interviews revealed a degree of 'consistency within the inconsistency'. A pattern that emerged from the responses was that management believed that there was a high degree of consultation with staff, whilst staff believed that they were not adequately consulted. Another interesting finding, which was acknowledged by some of the managers 
through hindsight, was that the right people may not have been consulted. In some instances, the heads of sections were chosen to lead the configuration for their particular sections and were tasked with consulting subordinates. However, such consultation did not take place.

\section{Configuration, the approach and the project plan during migration}

An important finding, which was highlighted by one respondent, was that configuration had been done in a vacuum. This respondent argued that configuration was done using the test server and they could not see the results of their configuration. After the implementation, it had become abundantly clear that the configuration had been well below par. This inefficiency in the system was not through lack of trying on the part of the staff that were configuring but rather that they had very little idea of what the end-product would look like.

As indicated in the literature, institutions migrating should pay more attention to the implementation approach. There are advantages and disadvantages to the 'big bang' and phased approaches. It would be a worthwhile practice for those that are configuring to be able to work in an environment that is currently running that particular product. The comments by Myhill (2000) about staff configuring in an environment where they could see the fruits of their work should be given due consideration when deciding on the configuration process. All three institutions surveyed used the 'big bang' approach for the migration process.

The 'big bang' approach was complicated by a project plan with very little flexibility. The tight project plan meant that "training and completing of the mapping was too close", as indicated by one of the project directors. Two institutions had problems with this plan due to limited time constraints, whilst the one institution managed to operate within its deadlines. Tight project plans, when dealing with an international supplier, are understandable. However, there should be an element of flexibility when dealing with local suppliers. Unfortunately, there was a claim by the interviewees that the local supplier was on the same learning curve as the client and in fact, in some instances, was less knowledgeable of the system than the client. It would seem that best practice centres around the view by Khurshid and Kadry (2006: 87) that project plans be realistic and sufficiently flexible.

\section{Training and evaluation}

There are undoubted benefits of dealing directly with the UK office of Sirsi. Unfortunately, there are also negatives such as having to be trained by a person with a foreign accent and pronunciation as claimed by one of the respondents. On the flip side, those that were trained by locals had to engage with trainers that were not comfortable with the system and were themselves still learners. It was a case of "the blind leading the blind".

The issue of training is crucial for the efficient usage of the system. Given the significance of training, it would have been safe to assume that the clients would be in a position to make demands of the supplier. However, the clients, that is, the libraries, had limited choices with regard to training. The schedules were tight and the trainers were prescribed. Further, the number of staff that could be trained was limited which gave credence to the principle of cascade training. However, in hindsight, it was acknowledged by respondents that there could have been a better choice of cascade trainers.

The authors are strong proponents of the view that all staff should be trained by the supplier. However, if that is not possible, then a core group, including those with technical expertise, should be trained on a live system by the international office in the UK. One of the institutions paid RI I m for the product and almost R200 000.00 for the training. That expenditure could have carried greater value if a core group was trained at headquarters.

The literature recommends that there should be a post implementation evaluation. The fact that the three institutions in $\mathrm{KZN}$ are in the throes or near finalization of implementation means that an evaluation is premature.

\section{I.3 Future development: buy or build?}

It is argued by the authors that libraries that continuously engage in research will keep pace with trends in the industry and will be in the advantageous position to recognize the option of developing its own system. Evans (1999) demonstrates the pedigree of the Urica system, a system that was developed locally and exported to a number of European countries. This is a clear indication of the capacity available in South Africa. The next time a library contemplates migration, the authors make the assertion that due cognizance must be given to 'building' instead of just resorting to 'buying'. 


\section{Conclusion and recommendations}

Three major institutions in KZN have migrated from Urica to Unicorn. There is no doubt that substantial thought went into the choice of the Unicorn system. Given the circumstances and the fact that there is "much of the same muchness" between systems (as indicated by one of the respondents in the survey), the choice of system cannot be criticized.

The authors recommend that there be an investigation into the possibility of developing a South Africa product which will ensure the retention of financial resources within the country. The process will also create job opportunities for local communities and, more importantly, generate local know-how and expertise.

There has been discussion in this paper on issues with regard to the migration to a new ILS. The authors recognize that there is some level of synergy between the discussion in the literature with regard to rollout and the rollout of the Unicorn system in KZN. However, criticism MUST be leveled against the KZN institutions for not exercising their consumer rights. The impression created from the interviews was that the vendor was in control and prescribed many of the processes in accordance with their capabilities as opposed to addressing the needs of the client. The client had to conform as opposed to the vendor conforming. As product consumers, the said institutions should not have let this happen.

\section{References}

ALA. 2003. Library technology reports. Available at www.techsource.ala.org. Accessed on 16 April 2007.

Bless, C. and Higson-Smith, C. 2000. Fundamentals of social research methods: an African perspective. 3rd ed. Cape Town: Juta. Bowden, V.M. 1985. Implementing change: the installation of an integrated system at UTHSCSA. Bulletin of the Medical Library Association, 73(3): 27I-277.

Breeding, M. 2007. An update on open source ILS. Computers in libraries, 27(3): 27-29.

Breeding, M. 2006. Knitting systems together. Computers in libraries, 26(9): 32-35.

Breeding, M. 2005. Looking toward the future of library technology. Computers in libraries, 25(5): 39-4I.

Cannell, S. and Guy, F. 200I. Cross-sectoral collaboration in the choice and implementation of a library management system: the experience of the University of Edinburgh and the National Library of Scotland. Program, 35(2): I35-I56.

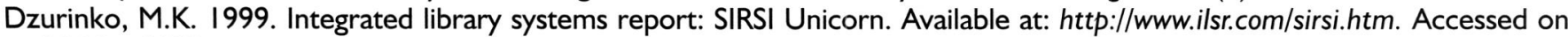
09 May 2007.

Eight Jordanian universities to implement Dynix. 2005. Managing information, 6(12): 29.

Equity firm buys SirsiDynix. 2007. American libraries, 38(2): 23. Available at: http://search.ebscohost.com. Accessed on 12 May 2007.

Evans, P. 1999. Peter Evans reviews the latest trends and happenings... Biblio tech review: information technology for libraries, Available at www.biblio-tech.com/btr999/May_99/lis_99.html. Accessed on 2 May 2007.

Greeff, M. 2005. Information collection: interviewing. In de Vos, A.S., Strydom, H., Fouche, C.B. and Delport, C.S.L. Research at grass roots: for social sciences and human service professions. $3^{\text {rd }}$ ed. Pretoria: Van Schaik. pp. 286-3I3.

Kaniki, A.M. 1999. Doing an information search. In Terre Blanche, M. and Durrheim, K. (eds.). Research in practice: applied methods for the social sciences. Cape Town: University of Cape Town Press. pp. 17-28.

Karetzky, S. 1998. Choosing an automated system. Library journal, I23(II): 42-44.

Khurshid, Z. and Kadry, M. H. 2006. Data migration from DOBIS/LIBIS to Horizon: experiences from the KFUPM Library in Saudi Arabia. Program, 40 (I): 74-88.

May, T. 1999. Social research: issues, methods and process. 2nd ed. Buckingham: Open University Press.

Myhill, M. 2000. Time for change: a personal insight into library systems' implementation: experiences at Exeter University Library. Program, 34(I): 89-101.

Ownes, D. 2006. Findability enabled. Library Journal, |31 (13): 30-32.

Pace, A. K. 2005. Helping you buy: integrated library systems. Computers in libraries, 25(8): 25, 32.

Raju, R., Raju, J., Moodley, S.R. and Jagarnath, O. 2007. A department of Innovation in an LIS structure: a luxury or a necessity? Mousaion. In Press.

Ryan, T. 2004. Turning patrons into partners when choosing an integrated library system. Computers in libraries, 24(3): 6-8, 54, 56.

Salisbury, R. 1999. Implementation of the Unicorn library management system at Reading University Library. Program, 33(2): 129-140.

Schulman, S. 1996. The myth of upgrading library systems. Information today, 13(7): 32.

Scott, D. 2006. Musing about SirsiDynix's new investment partner. Available at $h t t p: / / w w w . c o f f e e c o d e . n e t / a r c h i v e s / / 08-M u s i n g-$ about-SirsiDynixs-new-investment-partner.html . Accessed on 15 May 2007.

Seeman, C. 2003. Migrating successfully. Library journal, 128(17): 16-18.

Tennant, R. 2007. Dawn of a new era. Library journal, 132(3): 27.

Wayne, R. 2006. Helping you buy: integrated library systems. Computers in libraries, 26(9): 23-31.

Zhang, W. 1998. Selection of library automation systems: a management perspective. Journal of educational media and library sciences, 36(I): I-19. 


\section{Appendix}

\section{Semi-structured interview questions: The migration of integrated library systems with special reference to the rollout of Unicorn in the province of KZN}

\section{Preliminary questions}

Identify why there was a need to change the system. What system was the library using before the migration? Who was the library using as its support for the previous system? What has it cost the library to purchase the new system?

Item I: What were the features, in the Unicorn system, that persuaded your organisation to adopt the system?

Item 2: Please outline the structure of the systems department that was in place before consideration of change and the structure post decision made? Has there been a drastic change in structure to accommodate the migration?

Item 3: What role did your ICT Division play in the determination of the technical requirements and the supply thereof in the migration?

Item 4: What level of support do you currently get from your ICT Division?

Item 5: Can you indicate the level of consultation with regard to the configuration, that is, were the staff at the coal-face consulted?

Item 6: In hindsight, do you believe that the right people were consulted with regard to configuration?

Item 7: Please comment on the flexibility of the supplier in the provision of the necessary components including training, loading of data and such.

Item 8: Did you deal directly with the supplier or did you deal with an intermediary like UKS? Do you feel that you would have had a more successful process if you had to deal with the supplier directly?

Item 9: Do feel that the training could have been handled differently, for example: a more protracted and in-depth training process, better qualified trainers; more technical expertise being shared? Do you feel that you got value for money with regard to training? Please comment on the competencies of the trainers.

Item 10: How were the cascade trainers chosen? What skills were you looking for when making such a choice? Do you feel that the cascade trainers had been sufficiently acquainted with the system when they were engaging in cascade training?

Item I I: How long did it take to rollout the system? Were there any delays with the period of the rollout? Can you comment on the flexibility of the rollout process? Do you believe that the library as a system was ready for the rollout?

\section{Closing question:}

Do you feel that the rollout could have been done differently? 